\title{
应用抑制性消减杂交技术克隆鉴定肾癌 特异表达基因
}

张 强( ${ }^{(1)}$ 张志文 ${ }^{(2)}$ 龚 㑆 ${ }^{(1)}$ 辛殿旗 ${ }^{(1)}$ 那彦群 ${ }^{(1)}$ 郭应禄 ${ }^{(1)}$ (1)北京大学第一医院泌尿外科研究所, 北京 100034; (2)北京大学医学部生理系, 北京 100083. Email: zhanqian@public3.bta.com)

摘要 应用抑制性消减杂交技术(suppression subtractive hybridization, SSH), 成功地构建了高消减 效率的人肾癌组织与正常肾组织差异表达的 cDNA 消减文库, 从中随机挑取 200 个克隆进行酶切 分析, 结果显示其中 190 个均得到 50 400 bp 插入片段, 10 个无插入片段. 对其中 10 个插入的 cDNA 片段进行测序后经 GenBank 检索表明 10 个片段均为未知新序列, 其中 RCC18 为 5 个拷贝, 这提示以上 10 个 cDNA 片段可能来自 6 个新基因. Northern 杂交差异表达分析显示 RCC18 在肾 癌组织中有明显表达, 而在正常肾组织中无表达, 这证明 RCC18 是肾癌特异表达的新基因, 依杂 交信号估算其转录基因全长约 $3.5 \mathrm{~kb}$. 人肾癌 $\mathrm{cDNA}$ 消减文库的建立为进一步大批量篮选、克隆 肾癌特异性表达的未知新基因奠定了基础. 初步篮选出的特异性表达的新基因片段为进一步研究 基因功能及其临床意义提供了依据.

关键词 肾肿瘤 癌 抑制性消减杂交 基因 文库

肾癌的发生、发展与多种基因的突变与表达异常有关. 本研究应用抑制性消减杂交技术构 建了由肾癌和正常肾组织之间差异表达的 cDNA 片段组成的 cDNA 消减文库, 并且从中克隆 出肾癌特异表达的未知新基因片段, 为今后进一步研究肾癌特异表达基因的功能奠定了基础.

\section{1 材料与方法}

（1）肾癌和正常肾组织来源. 52 岁男性患者, CT, MRI, B 超均诊断为左肾中上极癌 $3 \mathrm{~cm}$ $\times 2 \mathrm{~cm}$, 未转移. 行左肾癌根治术, 标本病理证实为左肾中上极透明细胞癌, Gleason 分级以 $\mathrm{G} 2$ 为主, 部分为 $\mathrm{G} 1$, Robson 分期为 T2. 同时取肿瘤组织与远离肿瘤 $5 \mathrm{~cm}$ 以上的正常组织(经 病理证实), 切除的标本组织块立即以液氮处理, $-80^{\circ} \mathrm{C}$ 冻存.

(2) 肾癌及正常肾组织 poly $(A)^{+}$mRNA 的提取. 肾癌及正常肾组织各 $200 \mathrm{mg}$, 使用 mRNA Purification 试剂盒(Pharmacia Biotech), O1igo (dt)-Cell $\mu$ Lose 柱层析法直接提取 po1y $(\mathrm{A})^{+}$RNA, 严格按说明书操作并进行定性定量分析.

(3) 抑制性消减杂交. 应用 PCR-Select cDNA Subtraction 试剂盒, $50 \times$ PCR Enzyme Mix (均为 Clontech)进行 SSH 操作. (i ) 双链 $\mathrm{cDNA}\left(\mathrm{dscDNA}\right.$ )合成: 按 Diatchenko $\mathrm{o}^{[1]}$ 的方法进行, 取 poly(A) RNA $4 \mu \mathrm{L}(2 \mu \mathrm{g})$ 和 cDNA 合成引物 $1 \mu \mathrm{L}, 70^{\circ} \mathrm{C}$ 退火结合 $2 \mathrm{~min}$ 后, 加入白血病病毒 (MMLV)逆转录酶 $(200 \mathrm{U})$ 及 $\mathrm{dNTP}$ 组成反应体系, $42^{\circ} \mathrm{C}$ 延伸 $1.5 \mathrm{~h}$. 立即在单链 cDNA(sscDNA) 合成体系中加入 DNA 聚合酶 I, RNase H, E.coli DNA 连接酶, dNTP 组成总体积 $80 \mu \mathrm{L}$ 的反 应体系, $16^{\circ} \mathrm{C}$ 孵育 $2 \mathrm{~h}$ 后加入 $6 \mathrm{U} \mathrm{T} 4 \mathrm{DNA}$ 聚合酶, $16^{\circ} \mathrm{C}$ 再反应 $30 \mathrm{~min}$ 后, $95 \%$ 乙醇 $/ 4 \mathrm{~mol} / \mathrm{L}$ 乙酸 钠沉淀 dscDNA, 并溶于 $50 \mu \mathrm{L}$ 水中. (ii) 肾癌 dscDNA 经 Rsa I 酶切后与两种接头衔接: 将 合成的 dscDNA $43.5 \mu \mathrm{L}$ 用 $15 \mathrm{U} R s a \mathrm{I}$ 在 $37^{\circ} \mathrm{C}$ 酶切 $5 \mathrm{~h}$ 后, $95 \%$ 乙醇沉淀, 并溶于 $5.5 \mu \mathrm{L}$ 水中. 以肾癌为 Tester (试验方), 正常肾为 Driver (参照方), Tester dscDNA 以 $1: 6$ 稀释后, 分为两 
组, 各 $2 \mu \mathrm{L}$, 分别为 Adaptor 1,2 (接头 1,2 )连接, $16^{\circ} \mathrm{C}$ 反应过夜后进行连接效率检测. (iii) 两 次消减杂交: 在鉴定连接效率满意 $(>25 \%)$ 后, 将连接有 Adaptor 1 和 Adaptor 2 的 Tester dscDNA1.5 $\mu \mathrm{L}$ 分别与 $1.5 \mu \mathrm{L}$ Driver dscDNA 在 $68^{\circ} \mathrm{C}$ 下杂交 $8 \mathrm{~h}$ 后, 立即将两组经过第 1 次消 减杂交的体系混合, 另加新变性的 Driver cDNA $1 \mu \mathrm{L}, 68^{\circ} \mathrm{C}$ 杂交过夜.加 $200 \mu \mathrm{L}$ 缓冲稀释. (iv)两 次抑制性 PCR(巢式 PCR)及抑制效率检测: 取 $1 \mu \mathrm{L}$ 稀释后的第 2 次杂交后的产物, 在 $50 \times$ Advantage Klen Taq 聚合酶作用下, 以 Adaptor 1 及 Adaptor 2 的外侧序列分别为 $5^{\prime}$ 及 $3^{\prime}$ 引物 $\left(5^{\prime}\right.$ 引物序列: 5' -GTAATACGACTCACTATAGGGC-3'，3' 引物序列: 5' -TGTAGCGTGAAGACGACAGAA-3' ) 进行第 1 次 PCR 扩增 (PCR 扩增仪为 Perkin Elemer DNA Thermal Cycler 480). 取 第 1 次 PCR 产物 $3 \mu \mathrm{L}, 1: 10$ 稀释后取 $1 \mu \mathrm{L}$, 在 $50 \times$ Advantage Klen Taq 聚合酶作用下, 以 Adaptor 1(5' -GTAATACGACTCACTATAGGGCTCGAGCGGCCGCCCGGGCAGGT-3 ' ; 3' CCCGTCCA-5' $)$ 及 Adaptor 2(5' -TGTAGCGTGAAGACGACAGAAAGGGCGTGGTGCGGAGGGCGGT-3' ; $3^{\prime}-$ GCCTCCCGCCA-5' $)$ 的内侧序列分别为 $5^{\prime}$ 及 $3^{\prime}$ 的巢式 PCR 引物(5' 引物序列: 5TCGAGCGG- CCGCCCGGGCAGGT-3'，3' 引物序列: 5' -TCGAGCGGCCGCCCGGGCAGGT$3^{\prime}$ )进行第 2 次 PCR 扩增, 并进行 PCR 产物消减效率检测(将未经抑制消减的肾癌 cDNA 同 时进行 PCR 对照).

(4) cDNA 消减文库的构建与初步篮选、克隆、鉴定. 按 Clark 等人 ${ }^{[2]}$ 的方法, 应用 Advantage PCR Cloning 试剂盒(Clontech 公司). 取 $3 \mu \mathrm{L}$ (约 $8 \mathrm{ng}$ ) PCR 产物及 $2 \mu \mathrm{L}$ PT-Adv 线 性化质粒载体, 在 $1 \mu \mathrm{L}$ (4 Weis 单位) T4 DNA 连接酶的作用下, 按摩尔比率 $1: 1$ 建立总体积 $10 \mu \mathrm{L}$ 的反应体系, $14^{\circ} \mathrm{C}$ 反应过夜后, $-20^{\circ} \mathrm{C}$ 保存. 取 $2 \mu \mathrm{L}$ 连接反应产物, 加入含 $2 \mu \mathrm{L} \beta$-颈基 乙醇的 $50 \mu \mathrm{L}$ 感受态大肠杆菌 Top $10 \mathrm{~F}^{\prime}$ (Clontech 公司)中, 经水浴、热休克, 另加 $250 \mu \mathrm{L} \mathrm{SOC}$ 液, 置 $37^{\circ} \mathrm{C}$ 水浴中, $225 \mathrm{r} / \mathrm{min}$ 摇菌 $1 \mathrm{~h}$, 取 $200 \mu \mathrm{L}$ 菌液种植于含 $50 \mu \mathrm{g} / \mathrm{mL}$ 氨苠青霉素的 $\mathrm{LB} / \mathrm{X}-\mathrm{gal} / \mathrm{IPTG}(\mathrm{Gibco})$ 培养板上, $37^{\circ} \mathrm{C}$ 培育 $18 \mathrm{~h}$. 计数培养板中直径 $>1 \mathrm{~mm}$ 的清晰白色及蓝色 菌落数, 随机挑取 200 个白色菌落, 按 Sambrook 等人 ${ }^{[3]}$ 的方法制备质粒, 并进行 EcoR I (Promega) 酶切分析. 随机挑取 10 个含插入片段的质粒, 用 M13 正向引物 $\left(5^{\prime}-\right.$ GTTTTCCCAGT- CACGAC-3' ) 测序, 测序采用 Pharmarcia Biotech 公司的 ALFTM DNA Sequencer 系统, 引物合成及序列分析由赛百胜公司代理. 测序结果送 GenBank (http://www.ncbi.nlm.gov/BLAST)检索分析.

（5） Northern 杂交鉴定差异表达基因. 将序列分析后显示可能来自新基因的 cDNA 片段 制成探针, 经 High Pure PCR Product Purification 试剂盒(Boehringer Mannheim)纯化, Randompriming DNA Labeling 试剂盒(Promega)标记 $\left[\alpha-{ }^{32} \mathrm{P}\right] 1.11 \times 10^{14} \mathrm{~Bq} / \mathrm{mmol}((3000 \mathrm{Ci} / \mathrm{mmol})$, Amersham Co.), 用 Tester 和 Driver 的总 RNA 各约 $30 \mu \mathrm{g}$ 进行 Northern 杂交分析, 尼龙膜为 Life Science 公司产品, 具体方法参照说明书及文献[3].

\section{2 结果}

\section{1 mRNA 的定性定量分析}

紫外分光光度仪(Pharmarcia Biotech)检测显示共提取肾癌及正常肾 po1y $(\mathrm{A})^{+}$RNA 分别为 $5.08 \mu \mathrm{g}$ 和 $5.12 \mu \mathrm{g}$, 吸光度 260 /吸光度 $280>1.90,1.0 \%$ 琼脂糖电泳见 mRNA 为 $>0.5 \mathrm{~kb}$ 清晰彗 尾片状条带, 证实 mRNA 质优量足(图 1). 


\section{2 dscDNA 两端连接效率检测}

dscDNA 与接头连接效率的高低是决定抑制性消减杂交成 败的最关键步骤. 将连接有 Adaptor 1 和 Adaptor 2 的两组肾癌 dscDNA 分别用 G3PDH $3^{\prime}, 5^{\prime}$ 引物及以 G3PDH3' 引物和接头 部序列为 $5^{\prime}$ 引物进行 35 个循环扩增, 产物用 $2.0 \%$ 琼脂糖凝胶 电泳鉴定. 结果显示, 两组肾癌 dscDNA 连接效率均 $>80 \%$, 说 明 $80 \%$ 以上 dscDNA 已与接头连接(图 2).

\section{3 cDNA 消减文库消减效率的鉴定}

此步骤是评价消减文库价值的决定性环节, 各取 $1 \mu \mathrm{L}$ 抑制 性 PCR 产物和非抑制性 PCR 产物为模板, 分别用看家基因 G3PDH 及肾癌中高表达而正常肾中表达很低甚至不表达的癌 基因 $c-m y c$ 片段 ${ }^{[4]}$ 的引物进行 PCR 扩增, PCR 反应体系为 $30 \mu \mathrm{L}$, 分别在 $25,30,35,40$ 个循环结束时从体系中吸取 $5 \mu \mathrm{L}$ 进行电泳鉴定, 结果显示, 与非抑制性 PCR 产物相比, 抑制性 PCR 产物中非特异性表达 G3PDH 基因产物大大减少(图 3), 而特异性高表 达的 $c-m y c$ 基因大量富集(图 4), 说明所构建的消 减文库具有很高的消减效率.

\section{4 cDNA 消减文库扩增及克隆的序列分析鉴定}

扩增后 cDNA 消减文库包含约 350 个白色克 隆和 40 个蓝色克隆, 克隆饱满清晰. 随机挑取 200 个白色克隆, 制备质粒后, 予 EcoR I 酶切分

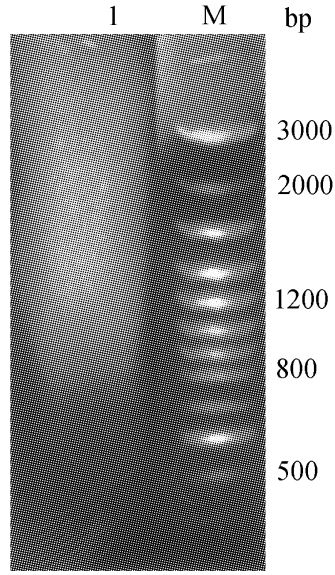

图 $1 \mathrm{mRNA}$ 凝胶电泳 分析结果显示: mRNA 呈清晰彗 尾状条带

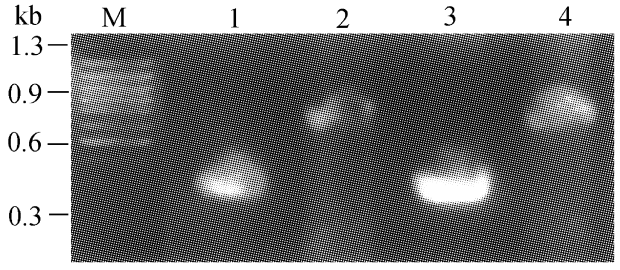

图 $2 \mathrm{dscDNA}$ 两端连接效率凝胶电泳鉴定 第 1,2 道为与 adaptor 1 连接组, 第 3,4 道为与 adaptor 2 连接组, 第 1,3 道以 $\mathrm{G} 3 \mathrm{PDH} 3^{\prime}, 5^{\prime}$ 引物, 第 2,4 道以 $\mathrm{G} 3 \mathrm{PDH} 3^{\prime}$ 引物和接头部序列为 $5^{\prime}$ 引物, 结 果显示灰度比值: 第 2 道/第 1 道、第 4 道/第 3 道 均大于 $80 \%$ 析, 190 个克隆均载有 50 400 bp 大小插入片段(图 5), 与理论设计大小相符. 测序表明随机

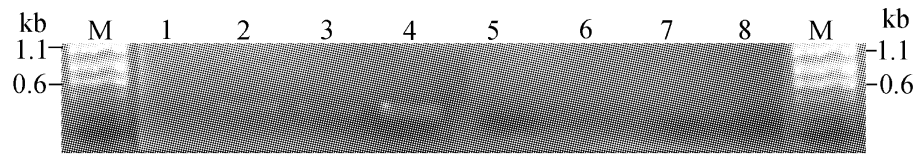

图 $3 G 3 P D H$ 基因片段扩增后丰度降低

第 1,2,3 道为非抑制性 PCR 产物, 第 5, 6, 7 道为抑制性 PCR 产物, 第 1,5 道为 28 个循环后 产物, 第 2,6 道为 33 个循环后产物, 第 3,7 道为 38 个循环后产物, 第 4,8 道为 43 个循环后

产物

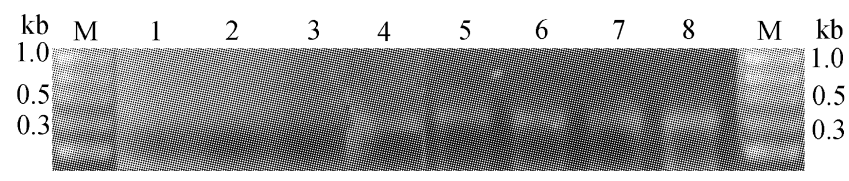

图 $4 c-m y c$ 基因片段扩增后丰度增高

图注同图 3 
挑取的 10 个 cDNA 插入片段大小为 100 300 bp, 经 GenBank 鉴定为 6 个未知新序列, 其中 RCC18 cDNA 片段为 $126 \mathrm{bp}$, 有 5 个拷贝.

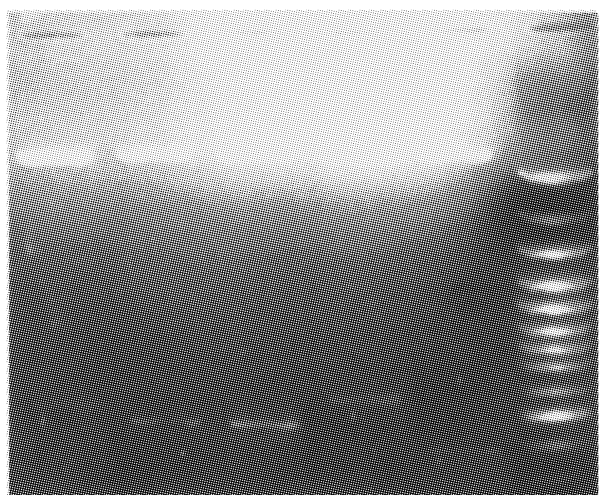

图 5 质粒酶切电泳分析 结果显示: 随机挑取的克隆中, 均载有 50 400 bp 大小 的插入片段 $\mathrm{bp}$

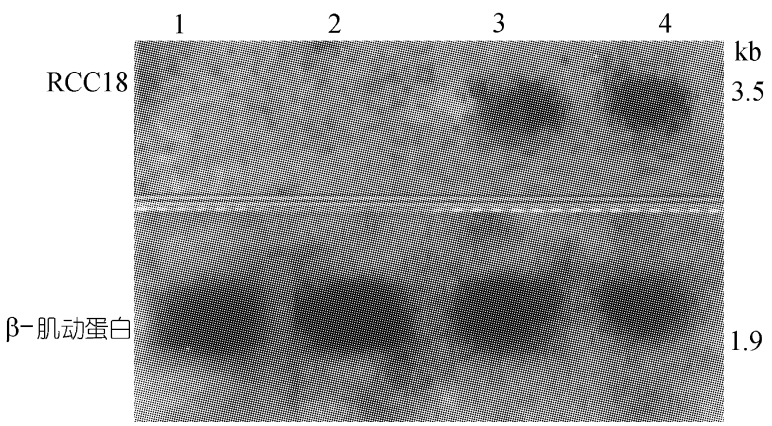

图 6 Northern 杂交分析显示: RCC18 在肾癌组织中 有明显表达而在正常肾组织中不表达 1,2 道为正常肾组织, 3,4 道为肾癌组织

\subsection{Northern 杂交差异分析结果}

以高拷贝 $\mathrm{cDNA}$ 片段 RCC18 为探针, 同位素标记后, 与两例肾癌及两例正常肾(临床随 机抽取, 经病理确诊)的 RNA 进行 Northern 杂交. 结果表明, RCC18 的全长约为 $3.5 \mathrm{~kb}$, 在肾 癌中有明显表达, 而在正常肾中未见表达(图 6).

\section{3 讨论}

肾癌是一种生物学行为奇特多变的肿瘤, 病因至今不清. 近年来遗传学研究表明肾癌是 一种多基因相关肿瘤 ${ }^{[57]}$. 目前国外研究的热点集中于对肾癌特异性基因的克隆与鉴定, 构建 一般的基因组文库或 cDNA 文库, 并进行篮选是较普遍的方法, 但因其特异性差, 篮选阳性 率低, 故进展较缓慢.

1996 年, Diatchenko 等人 ${ }^{[1]}$ 在抑制性 PCR 的基础上首次发明了抑制性消减杂交技术 (suppression subtractive hybridization, SSH), 并成功地构建了睪丸肿瘤特异性 cDNA 消减文库, 鉴定出了 42 个睪丸肿瘤特异的新基因. 此后 SSH 技术在国外相继应用于乳腺癌、肾上腺癌 等肿瘤特异性基因的克隆 ${ }^{[8]}$ 均取得成功. SSH 技术主要通过消减杂交将待比较双方 Tester (实 验方, 如肾癌)和 Driver(参考方, 如正常竖)的 mRNA 共同的部分消减, 再通过抑制性 PCR 特 异性扩增 Tester 特异表达的 cDNA 片段使 Tester DNA 中特异表达基因的 cDNA 得到大量的 富集. 它所构建的消减文库较普通的基因组文库或 CDNA 文库有两大突出的优点：（i ）高度 特异性: 通过 SSH 技术中装上接头、两轮消减杂交、两轮抑制性 PCR, 大量特异扩增那些代 表了差异表达的 cDNA 片段, 抑制了非特异性片段, 使各种消减文库特异性达 $60 \%$ 95\% ${ }^{[1,9,10]}$. (ii) 有一个归一化(normalization)过程, 使高、低丰度序列浓度变得一致. 实验证明, 经过一 轮消减即可对稀少片段几个分子富集 1000 5000 倍, 这样对低丰度的差异表达基因也能有效 地克隆 ${ }^{[9,11]}$, 这是普通基因组文库和 $\mathrm{cDNA}$ 文库无法达到的.

本研究应用抑制性消减杂交的方法, 经严格检验成功地用肾癌组织构建了高特异性的人 
肾癌 cDNA 消减文库, 并且肾癌及正常肾组织来源于同一临床标本, 排除了组织相容性抗原 基因差异的干扰. 经过消减效率鉴定表明，像看家基因 $G 3 P D H$ 这样非特异性表达的 cDNA 片段得到了高度抑制, 而相对正常肾特异性高表达的 $c-m y c$ 基因的 $\mathrm{cDNA}$ 得到了充分的富集, 这表明所构建的 cDNA 文库是高度特异的. 人肾癌 cDNA 消减文库构建的意义在于: 首先, 它 为大批量克隆肾癌特异性基因奠定了重要基础, 并大大减少了进一步应用 Northern 杂交, RTPCR，DNA 测序，RACE 等技术大批量篮选鉴定克隆肾癌特异基因、基因全长获得、基因功能 研究(作者正在试验中)的盲目性, 极大地提高了特异性, 并且有利于克隆出低丰度的稀有基因. 其次, 对消减文库的初步篮选已克隆出 6 个新基因的 cDNA 片段, 经 Northern 杂交分析表明, 高拷贝 cDNA 片段 RCC18 在肾癌和正常肾组织之间存在明显的差异, 而 GenBank 中检索不 到与 RCC18 全长有同源性的基因序列, 这表明 RCC18 为肾癌特异表达新基因. 这些特异表 达新基因的克隆为研究肾癌这一生物学行为奇特而发病分子机制不明的肿瘤的发生、发展机 理提供新的突破口. 第三, 更具有意义的是, 消减文库构建于人的肾癌组织, 因此所克隆的肾 癌特异表达基因具有重要的临床意义和应用价值，为肾癌的预防、早期特异性诊断、基因治 疗的研究提供了新的重要工具.

致谢 本工作为国家自然科学基金资助项目(批准号: 39870841).

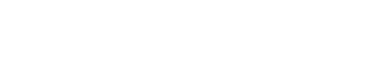

1 Diatchenko L, Lau Y F C, Campbell A P, et al. Suppression subtractive hybridization: a method for generating differentially regulated or tissue-specific cDNA probes and libraries. Proc Natl Acad Sci USA, 1996, 93(18): 6025 6030

2 Clark J M. Novel non-templated nucleotide addition reactions catalyzed by procaryotic and eucaryotic DNA polymerase. Nucleic Acids Res, 1988, 16(15): 9677 9686

3 Sambrook J, Fritsch E F, Maniatis T, et al. Molocular Cloning: A Laborogary Manual. 2nd ed. New York: Cold Spring Harbor, 1989. 18 24

4 Bhat H K, Springer I, Rajaraman S, et al. Immunocytochemical localization of $c$-myc and $C$-jun oncoproteins in hamster kidney and estrogen-induced kidney tumors. J Steroid Biochem Mol Biol, 1997, 60(2): 99 104

5 Linehan W M, Lerman M I, Zbar B. Indentification of the von Hippellindau (VHL) gene, it's role in renal cancer. JAMA, 1995, 273(2): 564 570

6 Hewitt S M, Hamada S, Mcdonel T J, et al. Regulation of the protooncogenes bcl-2 and c-myc by the Wilms' tumor suppressor gene WTI. Cancer Res, 1995, 55(18): 5386 5389

7 Walther M M, Jenning S B, Gnarra F R, et al. Molecular genetics of renal cell carcinoma. In: Vogelzang N J, Scandino P T, Shipley W U, et al. eds. Comprehensive Textbook of Genitourinary Oncology. Baltimore: Willianisk \& Wilkins, 1996. $160 \sim 170$

8 Kuang W W, Thompson D A, Hoch R V, et al. Differential screening and suppression subtractive hybridization identified genes differentially expressed in an estrogen receptor-positive breast carcinoma cell line. Nucleic Acids Res, 1998, 26(4): $1116 \sim 1123$

9 Gurskaya N G, Diatchenko L, Chenchik A, et al. Equalizing cDNA subtraction based on selective suppression of polymerase chain reaction: cloning of Jurkat cell transcripts induced by phytohemaglutinin and phorbol 12-myristaie 13-acetaie. Anal Biochem, 1996, 240(1): 90 97

10 Wong B R, Park C G, Lee S Y, et al. Identifying T-cell signaling molecules with the Clontech PCR-select cDNA subtraction kit. Clontechniques, 1996, XI(3): 32 33

11 Von S O D, Thies W G, Hofmann M, et al. A high throughput screening for rarely transcribed differentially expressed genes. Nucleic Acids Res, 1997, 25(13): 2598 2602 